\title{
Development and Characterization of Teflon-Copper Composite Material
}

\author{
IMRAN Hameed ${ }^{a}$, ABDUL Rauf ${ }^{\text {b, }}$, Faisal Nasim ${ }^{c}$, \\ Muhammad Siddique ${ }^{d}$ and Adnan Gul \\ Institute of Industrial Control System, P. O. Box.1398, Rawalpindi, Pakistan \\ aimranhameed68@hotmail.com, "babdulrauf3134@yahoo.com, 'zephyr64@gmail.com, \\ ddrsiddikbit@gmail.com
}

Keywords: Composite Material, Powder Metallurgy, Isostatic Pressing, Micro Hardness, Tensile Strength, Microstructure.

Abstract. Composites are a combination of materials that are mixed together to achieve specific structural properties. Powder metallurgy technique using hot isostatic pressing, a hybrid densification process in which pressure and temperature are applied at the same time, has been used to develop a Teflon ${ }^{\circledR}$-copper composite material. Three samples were prepared by changing the Teflon-copper composition as $60: 40 \%, 65: 35 \%$ and $70: 30 \%$ by weight. Commercially available powders of Teflon and copper of grain size $\sim 40 \mu \mathrm{m}$ was used. The aim to develop this type of material was to increase its density $\left(\sim 4 \mathrm{~g} / \mathrm{cm}^{3}\right)$, and hardness. The commercial applications of such type of composite material are solid lubricants, sleeves, bearings etc. In this paper the effect of composition on hardness, tensile strength and surface roughness is studied.

\section{Introduction}

In recent years there has been a significant growth in the large scale production of fiber and fiber reinforced epoxy matrix composites because of their remarkable properties. These are being used in aerospace, automotive and chemical industry on account of their good combination of properties. Fibers reinforced polymer composites are used for the manufacturing of number of mechanical components such as gears, cams, wheels, brakes, clutches, bush bearing and seals. Considerable efforts are being made to extend the range of applications. Such use would provide economical and functional benefits to both manufacturers and consumers. Various researchers have studied the tribological behavior of PTFE by varying shapes, sizes, types and compositions of fiber reinforcement in PTFE matrix. In general these materials exhibit lower wear when compared to pure polymers [1].

Polytetrafluoroethylene (PTFE) is a strong, tough, waxy, nonflammable synthetic resin produced by polymerization of tetrafluoroethylene and is known by such trademarks as Teflon, Fluo, etc. It consists of long-chain molecular structure. Its monomer consists of two carbon atoms each of them having flourine atoms attached, Fig. 1. Bonds within each chain are strong covalent bonds whereas the secondary bonds between two chains are weaker.

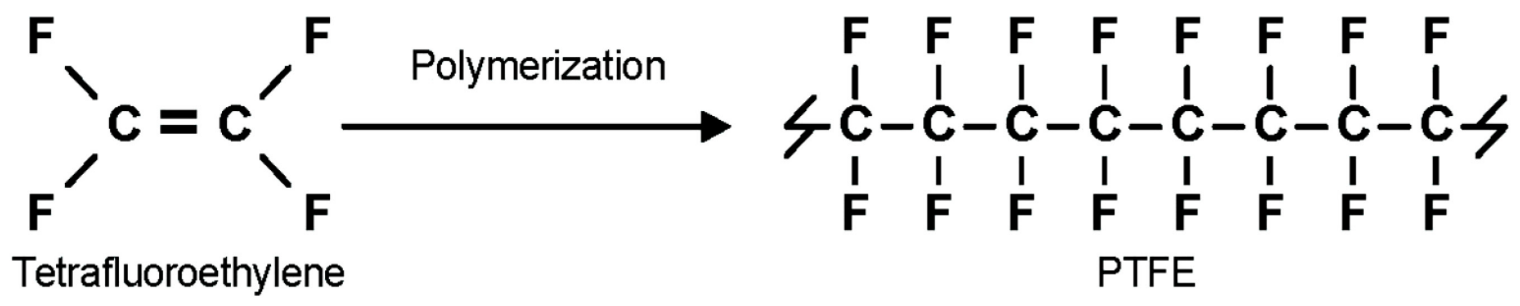

Fig. 1. Polymerization reaction of tetrafluoroethylene that yields PTFE

PTFE is distinguished by its slippery surface, high melting point and resistance against the attack of almost all chemicals. Micro friction studies guide us to understand how the composite material behaves and translate lubrication through shear layer phenomenon. PTFE maintains high strength, toughness and self-lubrication at low temperature down to $5 \mathrm{~K}$ and good flexibility at temperatures above $194 \mathrm{~K}$. 
Among all solid lubricants (SLs), PTFE proved most promising. The long PTFE fibers on the surface proved most beneficial as compared to other forms to improve tribological performance of composites without appreciable loss in the strength. PTFE fiber incorporation removed the stickslip problem associated with the unmodified surface; reduced coefficient of friction $\mu$ from 0.6 to 0.12 and enhanced the wear resistance $\left(\mathrm{W}_{\mathrm{R}}\right)$ approximately by 70 times. The placement of SLs however, was done manually and proper technique was not evolved in these preliminary studies [2-5].

In this paper, emphasis has been focused on application where increased hardness, and density are of prime importance. By raising temperature, the distance between the chains increases providing good adjustment of the atoms of other materials. Since from literature, copper mixed composite material was not available hence for this purpose copper particles reinforcement has been used to achieve the above properties. To develop such type of material, hot isostatic pressing also known as compression molding is used and its physical and mechanical properties are presented.

\section{Experimental Procedure}

Teflon and Copper in powder form were mixed together using powder metallurgy technique. Basically three methods are being used for powder compaction [6,7]. All three methods in the form of flow diagram are shown in Fig. 2.
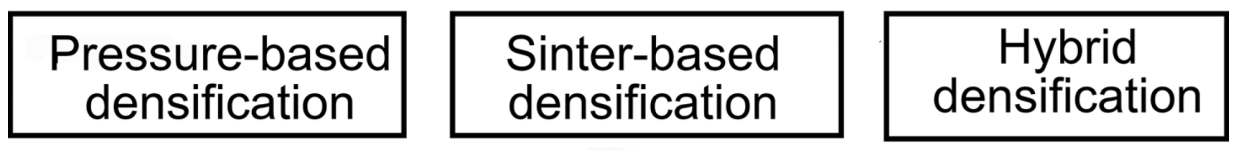

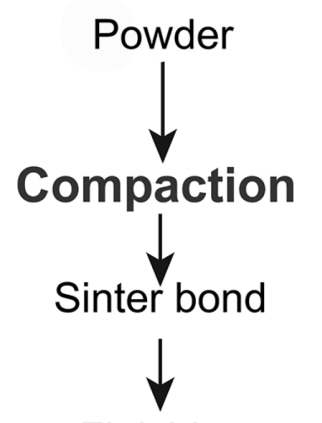

Finishing operations

Press and sinter

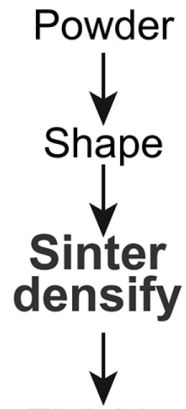

Finishing operations

Metal injection
molding molding

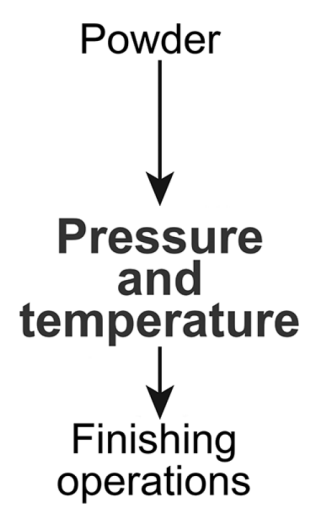

Hot isostatic pressing

Fig. 2. Three basic approaches to the consolidation of powders

From these approaches, Hybrid Densification Technique which is also known as hot isostatic pressing has been used to develop the composite material. In this technique, pressure and temperature are applied at the same time. During this process the die temperature is set so that the temperature of compacts reaches the desired range. Warm die is ideal for small to medium size parts [6].

The preparation process of the material started with the manual mixing of both the powders. Three samples were to be prepared by changing the Teflon-copper composition as $70: 30 \%, 65: 35 \%$ and $60: 40 \%$ by weight. Commercially available Teflon and copper powders of grain size $\sim 40 \mu \mathrm{m}$ were used in these experiments. After mixing, sieving was carried to remove the unwanted parts of the material as Teflon has sticky properties and small lumps may form during mixing. In order to get proper mixing of the material, the manual mixed powder was put in high speed grinding machine and mixed for 10-15minutes. The powder so obtained was again passed through fine sieves. The mixed powder was then transferred to a pre-heated compaction die maintained at a 
temperature of $300^{\circ} \mathrm{C}$. The compression was carried out by applying a pressure of $20 \mathrm{MPa}$ to remove any trapped gasses and soaked there for one hour. In the second step, the temperature of the die was increased up to $380^{\circ} \mathrm{C}$ and again compressed using $30 \mathrm{MPa}$ pressure for a dwell time of six hours. After six hours of soaking, the die along with component was cooled to room temperature. As the temperature of the die reached at the room temperature, the components were removed from the die and then machined to carry out the required tests. The schematic of die used for compaction is shown in Fig. 3.

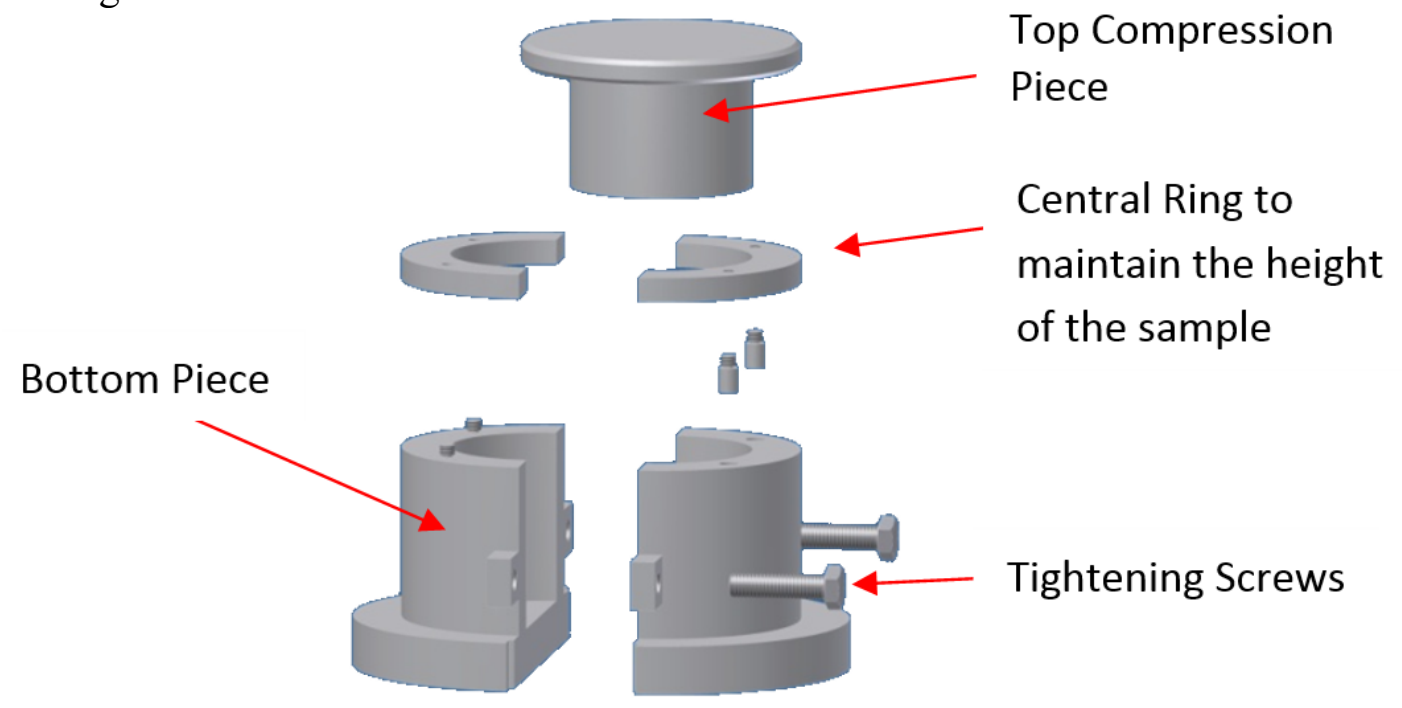

Fig. 3. Schematic diagram of die used for compaction of material

\section{Results and Discussions}

Physical and Mechanical properties. The aim to develop this type of material was to increase its density (to about $\sim 4 \mathrm{~g} / \mathrm{cm}^{3}$ ) and hardness. The achieved density of three samples is given in the Table 1.

Table 1. Densities achieved for different compositions

\begin{tabular}{|c|c|c|}
\hline S. No. & Composition (Teflon : Copper) & Density $\left[\mathbf{g} / \mathbf{c m}^{\mathbf{3}}\right]$ \\
\hline 1. & $70: 30$ (Sample A) & 3.8 \\
\hline 2. & $65: 35$ (Sample B) & 3.9 \\
\hline 3. & $60: 40$ (Sample C) & 4.2 \\
\hline
\end{tabular}

Hardness Measurements. According to standard procedure, polymers and composites are subjected to Shore-A or Shore-D hardness measurements. Therefore, Shore-A hardness was measured for all three composite samples. The results are given in the Table 2. Since the hardness of the material increased with increasing concentration of $\mathrm{Cu}$ in the composite, an increase in wear resistance was expected.

Table 2. Shore-A hardness of composite samples

\begin{tabular}{|c|c|c|}
\hline S. No. & Sample ID & Hardness \\
\hline 1. & A & 99.0 \\
\hline 2. & B & 99.7 \\
\hline 3. & C & 99.8 \\
\hline
\end{tabular}

Tensile Strength Analysis. The measured tensile strength of the three samples is presented in the Table 3. It can be seen that as $\mathrm{Cu}$ contents were increased in Teflon, the tensile strength decreases. The reason may be that the $\mathrm{Cu}$ granules do not make covalent bonds with the polymer, rather they are simply embedded in it, hence decreasing the tensile strength. 
Table 3. Tensile strength of composite samples

\begin{tabular}{|c|c|c|}
\hline S. No. & Sample ID & Tensile Strength $\left[\mathbf{M N} / \mathbf{m}^{\mathbf{2}}\right]$ \\
\hline 1. & A & 19 \\
\hline 2. & B & 17 \\
\hline 3. & C & 16 \\
\hline
\end{tabular}

SEM Analysis. All three samples were observed under SEM for microstructure and EDS analysis. The microstructures are presented in Fig. 4 and the corresponding EDS analysis in Table 4 which is the average of four readings. It is clear that $\mathrm{Cu}$ granules were embedded in Teflon base with some degree of inhomogeneity. Also EDS analysis confirmed the gradual increase in $\mathrm{Cu}$ concentration from Sample-A to Sample-C.

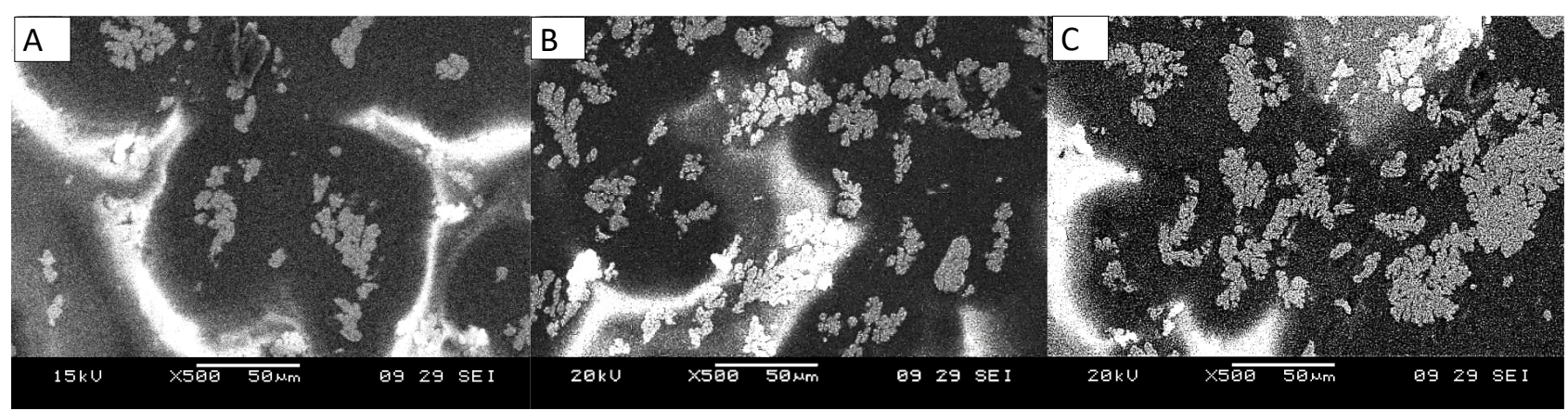

Fig. 4. SEM images of samples A-C

Table 4. EDS Analysis of the three composites (wt.\%)

\begin{tabular}{|c|c|c|c|}
\hline & \multicolumn{3}{|c|}{ Sample } \\
\cline { 2 - 4 } & A & B & C \\
\hline $\mathrm{C}$ & 25 & 23 & 21 \\
\hline $\mathrm{F}$ & 65 & 59 & 55 \\
\hline $\mathrm{Cu}$ & 10 & 18 & 24 \\
\hline
\end{tabular}

AFM Analysis. All three samples were subjected to AFM analysis for topography and surface roughness evaluation. Dynamic imaging mode of AFM was used to scan the samples while using Tap90Al-G cantilever made up SiN for scanning the surface. The results are shown from Fig. 5.

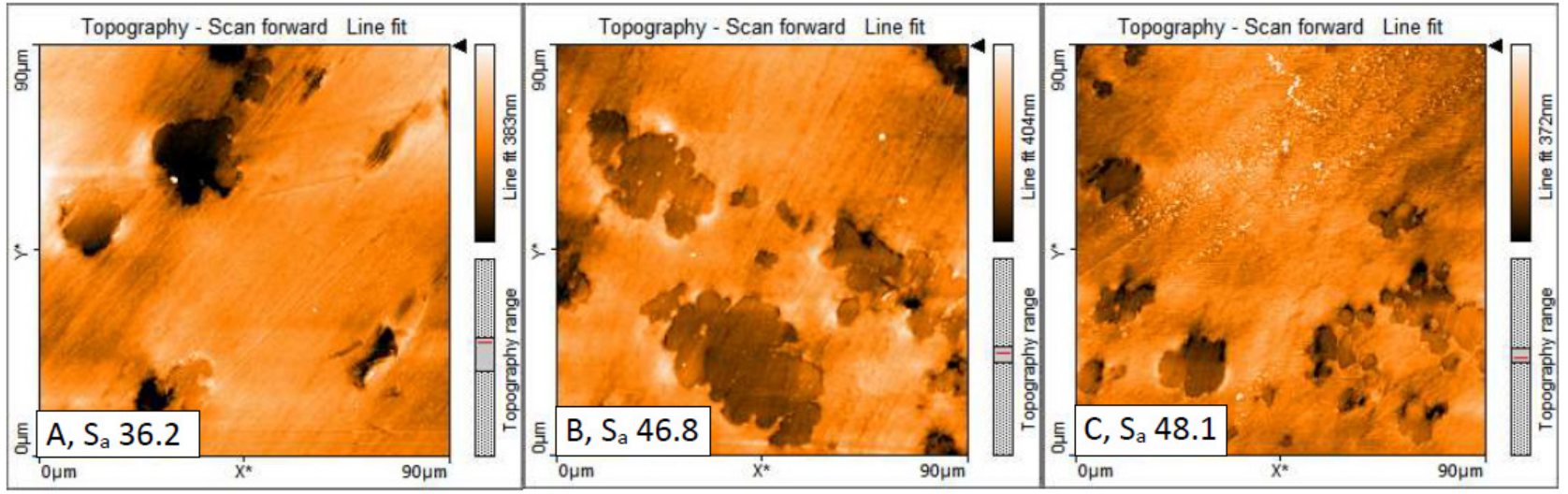

Fig. 5. Topography of samples A-C (left to right) and surface roughness $\left(\mathrm{S}_{\mathrm{a}}\right)$ values

It can be seen that $\mathrm{Cu}$ granules were embedded in the Teflon base material. The average surface roughness (Sa) was calculated using AFM software and it was in the range of 36-48 nm in $81 \mu \mathrm{m}^{2}$ area. 


\section{Summary}

On the basis of the above measurements following conclusions can be drawn:

1. By simultaneously applying suitable pressure and temperature, the desired density $\sim 4 \mathrm{~g} / \mathrm{cm}^{3}$ has been achieved.

2. The hardness of the material increased with increasing $\mathrm{Cu}$ concentration in Teflon.

3. The tensile strength of the material decreased with increase of $\mathrm{Cu}$ concentration.

4. The SEM analysis showed that the $\mathrm{Cu}$ granules were embedded in Teflon.

5. The AFM analysis showed that the average surface roughness $(\mathrm{Sa})$ varied in the range of $36-48 \mathrm{~nm}$ in $81 \mu \mathrm{m}^{2}$ area.

\section{Acknowledgement}

The authors acknowledge the contribution made by the 'measurement group' like microstructure, AFM analysis, tensile and SEM analysis.

\section{References}

[1] P. V. Kulkarni, N. K. Chapkhhane, Internat. J. Engineer. Adv. Technol., 1 (2012) 2249 2258.

[2] J. Bijwe, M. Sharma, Tribology of Nanocomposites, Materials Forming, Machining and Tribology, Springer-Verlag, Berlin, Heidelberg 2013.

[3] S. Bahadur, The development of transfer layers and their role in polymer tribology, Wear 245 (2000) 92-99.

[4] M. Sharma, J. Bijwe, Surface engineering of polymer composites with nano and micron sized PTFE fillers, J. Mater. Sci., 47 (2012) 4928-4935.

[5] S. Tiwari, J. Bijwe, S. Panier, Tribological studies on Polyetherimide composites based on carbon fabric with optimized oxidation treatment, Wear, 271 (2011) 2252-2260.

[6] W. B. James, Powder Metallurgy Methods and Applications, ASM Handbook, 7 (2015) 9-19.

[7] R. M. German, Powder Metallurgy \& Particulate Materials Processing, Metal Powder Industries Federation, Princeton, NJ. (2005) 155. 